
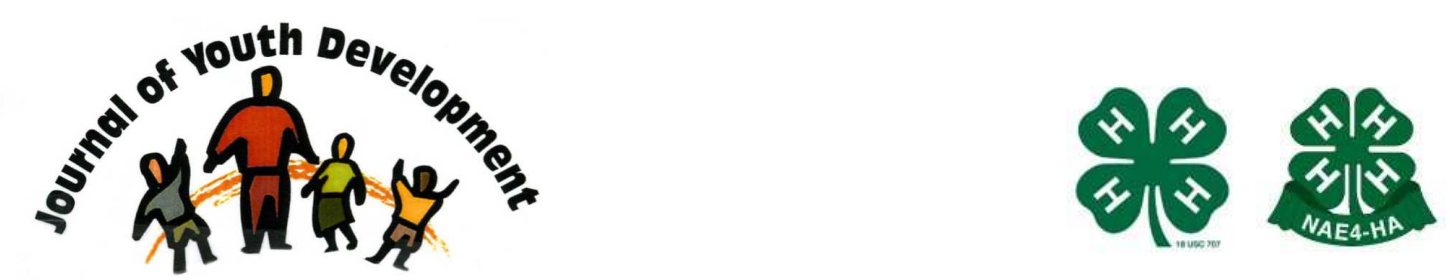

Bridging Research \& Practice

\title{
Integrative Literature Review of Adolescent Risk and Health Compromising \\ Behaviors Guided by the Problem Behavior Theory
}

Alice L. March

Capstone College of Nursing

The University of Alabama

Tuscaloosa, AL

almarch@bama.ua.edu 


\title{
JOURNAL OF YOUTH DEVELOPMENT \\ bridging research and practice

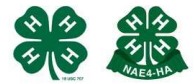

\section{Integrative Literature Review of Adolescent Risk and Health Compromising Behaviors Guided by the Problem Behavior Theory}

Alice L. March

The University of Alabama

\begin{abstract}
Twenty percent of the world's population is adolescents. Although generally healthy, risky behaviors result in premature death from injury and establish lifestyle choices which may give rise to poor health and disability during adult life. This integrative review presents the state of the literature related to adolescent health risk behaviors as framed by the problem behavior theory. The key word search using the databases of ERIC, CINAHL Plus with full text, PsycARTICLES, and PsycINFO yielded an internationally representative group of articles consistent with the guiding framework. Fifteen articles related to risk factors, protective factors, risk behaviors, and health-compromising behaviors of adolescents were retained from the past five years. Although the literature is replete with research involving adolescents, gaps are identified, and recommendations for future research are considered.
\end{abstract}

\section{Introduction}

Twenty percent of the global population is made up of adolescents. They are expected to be healthy, yet risky behaviors result in premature death from many causes including motor vehicle crashes, suicide, drug overdose, and violence (World Health Organization [WHO], 2009). During the journey from childhood to adulthood, lifestyles and habits are established. Choices such as tobacco, drug, and alcohol use, unhealthy eating habits, and physical inactivity result in subsequent impaired adult health, creating a social and financial burden to society. One third of chronic adult disease and two thirds of premature death relate to health behavior patterns established during adolescence (WHO, 2008).

This literature review is guided by problem behavior theory, a theory which attempts to explain a number of factors that drive decision during adolescence. The theory posits that certain forces push youth towards and pull them away from deviant or problem behaviors, creating a 
dynamic psychological state influencing their actions to reach socially defined goals (Jessor, Graves, Hanson, \& Jessor, 1968). The purpose of this integrative literature review is to use the theory-based framework to investigate the state of the literature related to risky behaviors of adolescents and identify gaps in the current knowledge base.

The leading cause of death among teens is unintentional injuries from motor vehicle crashes, drowning, and burns. In the United States (US), $85 \%$ of adolescents don't wear helmets when riding a bicycle, $11 \%$ don't wear seat belts, and $29 \%$ ride with people who have been drinking alcohol. Suicide and community/family violence are also leading causes of death among 15 to 19 year old people (WHO, 2008). In the US, more than $14 \%$ of teens report considering suicide, $7 \%$ report an actual suicide attempt, and $18 \%$ report carrying a weapon (Centers for Disease Control and Prevention [CDC], 2008).

Currently, 150 million teens use tobacco products (WHO, 2008). In a recent study, 20\% of U.S. students smoked cigarettes and $8 \%$ used smokeless tobacco. Alcohol and other drug use is even more prevalent with $75 \%$ reporting that they had tried alcohol at least once, $45 \%$ reported recent drinking, $26 \%$ drank five or more drinks of alcohol in a row, and $38 \%$ used marijuana (CDC, 2008).

Overweight and obesity is increasing in both low income and high income countries (WHO, 2008). In the US, $13 \%$ of students are obese and about $16 \%$ are overweight. Almost $65 \%$ do not meet recommended levels of physical activity and over 35\% watch at least 3 hours of television daily (CDC, 2008).

These statistics demonstrate that many adolescents are at risk of not remaining healthy, yet the data do not inform researchers of the risk and protective factors associated with participation in unhealthy and risky behaviors. This literature review will explore a portion of the available research about risk and protective factors and their relation to health risk and health compromising behaviors.

\section{Method}

The problem behavior theory, used to guide this review, has been the basis for empirical research for over 40 years and the literature would be overwhelming without placing some limits on the review. Therefore this review focused on publications between the years of 2004 to 2009. Databases included ERIC, CINAHL, PsycARTICLES, and PsycINFO. The key word search included adolescent, behavior, risk factors, and protective factors. Additional limiters were English language, peer reviewed, research, and journal articles.

Fifty articles were identified. Because the intent of this review was to examine research specifically using the guiding theory, 15 studies using the theory or models consistent with the theory were retained. With one exception, studies of middle school youths were not used as the definition of middle school varies making comparisons difficult. Because the literature review sought to discover research explicating the relationships within the model, studies of interventions and risk reduction programs were specifically excluded.

\section{Overview of Theoretical Framework}

The over arching theme of the problem behavior theory states conforming or deviant behaviors are goal directed. The term deviant refers to an action of a person, not the person. Cultural 
and societal groups identify deviant behaviors that require control (Jessor et al., 1968). Using a systems approach, each domain is comprised of instigation (risk factors) and control structures (protective factors) acting together to produce a dynamic state of proneness toward or against deviant behaviors. Behaviors are conceptualized as health compromising or health risk behaviors (Jessor, 1998). The framework presents multiple domains illustrating the relationships of variables, and their influence on health outcomes (See Figure 1). This literature review focuses on risk and protective factors, risk behaviors, and one risk outcome (depression). Early childbearing is delineated in the risk outcome domain of the model, but no related studies were retrieved using the specific search criteria, although it is very likely that they exist.

Figure 1

Interrelated Conceptual Domains of Risk Factors and Protective Factors

\section{Risk \& Protective Factors}

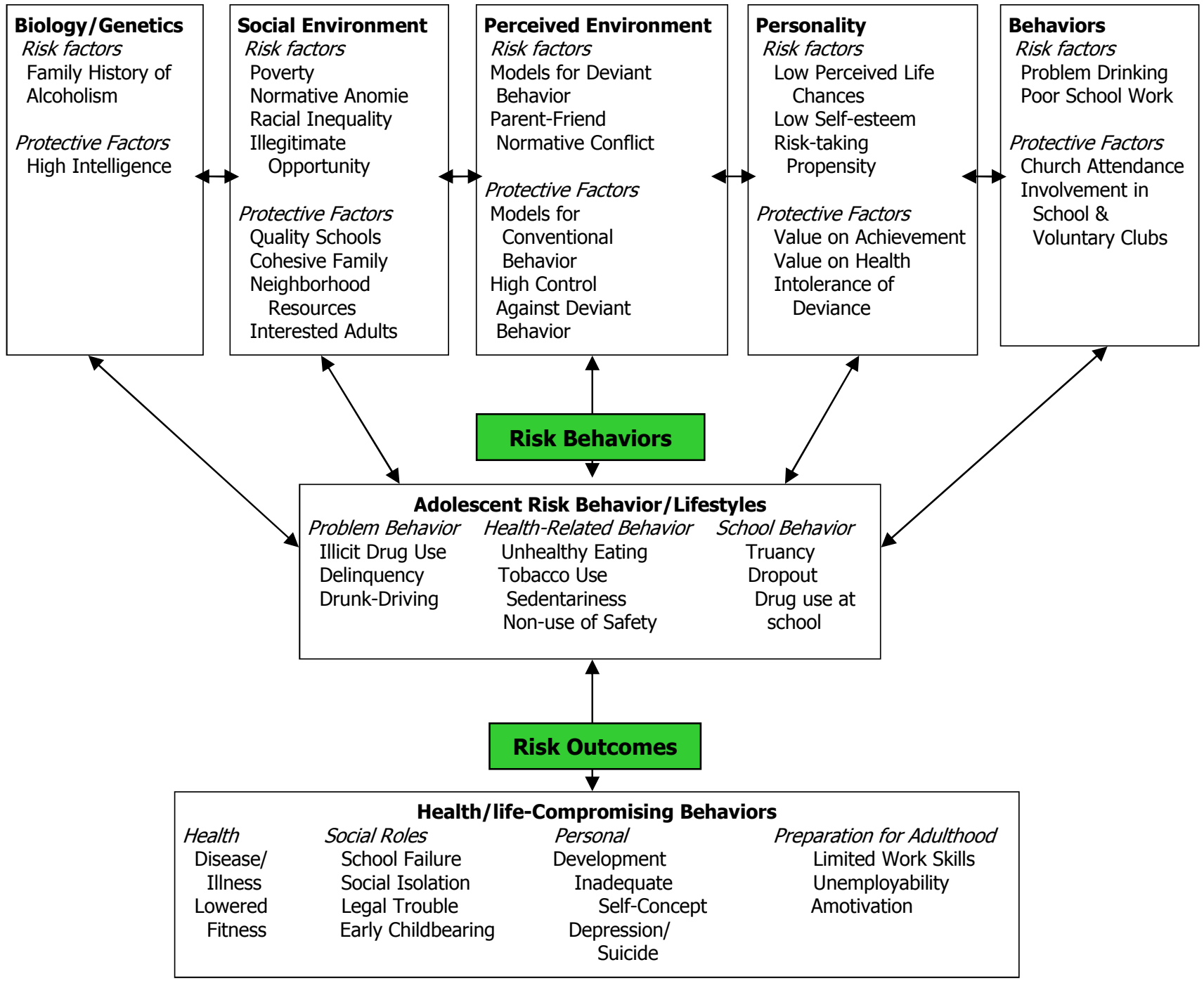




\section{Current Literature Regarding Risk and Protective Factors}

Current research findings are diverse and include results based of adolescent participants from majority and minority ethnic and racial populations. There are publications from around the world, including Australia, Canada, China, Georgia, Turkey, South Korea, Sweden, Switzerland, and the US.

\section{Biology and Genetic}

The risk and protective factors in the biology/genetics domain are family history of alcoholism and high intelligence (Jessor, 1998). No studies specific to the biology or genomics of problem behavior were found. However, increased funding in genetics research should produce new studies. The terms addiction and substance abuse history might have captured more publications.

Risk factors. Two conflicting studies examined family history of alcoholism. In one study, students reporting parental alcohol abuse, were more likely to report suicide ideation (Park, Schepp, Jang, \& Koo, 2006), yet the opposite was true in another study (Branstrom, Sjostrom, $\&$ Andreasson, 2007). Mixed findings about risk factors may result from operationalization of variables and from the truthfulness or social desirability of self-report.

Protective factors. Support for the protective effect of high intelligence was demonstrated by regression models predicting smoking behaviors when students reported grades of B or higher (Ellickson, Tucker, \& Klein, 2008). High intelligence was also protective against suicide ideation (Park et al., 2006). Students with learning problems, as a reverse proxy for high intelligence, were more likely to be in the deviant cluster, than the normal or problem cluster (Bartlett, Holditch-Davis, Belyea, Halpern, \& Beeber, 2006). Although these studies support high intelligence as a protective factor, consideration must be given to the operationalization of high intelligence. High intelligence may be protective, but it is difficult to improve this protective factor, except through school system improvements.

\section{Social Environment}

The social environment provides the tools necessary for achievement of goals. Certain groups are more likely to achieve success based on social standing, resulting in pressure to achieve goals by any means possible, including illegitimate actions (Jessor et al., 1968).

Risk factors. The social environment risk factors include normative anomie, poverty, racial inequality, and illegitimate opportunity (Jessor, 1998). There were no studies examining normative anomie. Parental procurement of alcohol was associated with problem drinking, supporting illegitimate opportunity as a risk factor (Branstrom et al., 2007).

The literature on racial inequality must be interpreted with caution, as poverty and race are deeply intertwined, and both result in disproportionate ability to attain goals. Race may be used as a control variable or to limit samples to a particular group (Bennett, 2007; Fitzpatrick, Piko, \& Miller, 2008). African American youth were more likely to change to a more deviant group or from a normal to a deviant group when compared with other races (Bartlett, et al., 2006). African American, Hispanic Americans, Pacific Islanders, and Asian Americans were more likely to be depressed or in the depression trajectory group when compared to Caucasians (Costello, Swendsen, Rose, \& Dierker, 2008). Contrary to the premise of race as a risk factor, African American identity was protective against early onset of smoking (Wills, Resko, Ainette \& Mendoza, 2004). 
Studies exploring poverty also report mixed results. Consistent with the expected effect of a risk factor, poverty was associated with depressed mood (Costello, et al., 2008) and high socioeconomic status (SES), was protective against suicide ideation (Park et al., 2006). In contrast, poverty was not a risk factor in low SES adolescents who were more likely to fall into the normal behavior group, while adolescents from the middle SES were more likely to belong to the deviant behavior cluster (Bartlett et al., 2006). Studies using poverty as a control variable failed to show a relationship between problem drinking and marijuana use (Branstrom et al., 2007), or marijuana and tobacco use (Graves, Fernandez, Shelton, Frabutt, \& Williford, 2005).

Mixed evidence of the effects of risk factors in the social environment on a broad array of adolescent behaviors was found. The mixed findings may be due to unmeasured social factors, distant to youth and therefore creating less of an effect. Variations in peer and neighborhood factors may also impact findings.

Protective factors. Quality schools, neighborhood resources, cohesive family, and interested adults are the protective factors of the social environment (Jessor, 1998). No studies of interested adults fit the search criteria. Quality schools and neighborhood resources were protective against use of alcohol, tobacco, and other drugs (ATOD) (Cleveland, Feinberg, Bontempo, \& Greenberg, 2008). Family cohesion was protective against smoking and as family support decreased, the likelihood of smoking increased (Ellickson, et al., 2008). Family support/attachment decreased the odds of ATOD use (Cleveland, et al., 2008) and was protective against problems from drug and alcohol use (Vazsonyi, et al., 2008). Family cohesion was also protective against depressed mood (Costello et al., 2008) and suicide ideation (Eskin, Ertekin, Dereboy, \& Demirkiran, 2007). Alternatively, studies found no relationship between parental support and problem behavior (Bartlett, et al., 2006; Bennett, 2007), or between family cohesion and suicide ideation or attempt (Fitzpatrick, et al., 2008).

Generally, social environment was a protective factor against ATOD use, deviance, problem drinking, depression, and suicide ideation. Although supporting cohesive families should protect adolescents, the premise that family influences become less as youth age, suggests that supporting both family and peer networks may be more effective in protecting adolescents.

\section{Perceived Environment}

The perceived environment includes societal norms which guide behavior and are protective (Jessor et al., 1968). The level of exposure to deviant behaviors and the social support for or against behaviors has a direct effect on the likelihood of deviant behavior. A high prevalence of risky or deviant behaviors provides opportunity to engage in those behaviors (Jessor \& Jessor, 1977).

Risk factors. Risk factors in the perceived environment include models for deviant behavior and parent-friend normative conflict (Jessor, 1998). Studies investigating parent-friend normative conflict were not found. Parent and peer models for deviant behavior were reported less often in younger adolescents, and increased in frequency in older youth (Wills et al., 2004). Parental criminality was associated with participation in problem behaviors (Bennett, 2007). Mixed results in relation to parental felony were reported, with increased tobacco use, but decreased marijuana use (Graves et al., 2005). 
Substance use activities by important adults such as parents, teachers, or other mentors provide models of deviant behavior. Youth with parents who used ATOD were more likely to smoke cigarettes and/or use marijuana (Graves, et al., 2005), and smoking by important adults was predictive of continued smoking (Ellickson, et al., 2008). Norm-breaking friends also provide models for deviant behavior, and students reporting such friends were more likely to report problem drinking (Branstrom, et al., 2007; Cleveland, et al., 2008), use marijuana (Branstrom, et al., 2007), and smoke cigarettes (Ellickson, et al., 2008).

Overall, the literature supports the risk factor of models for deviant behavior in an array of problem behaviors. The findings that models for deviant behaviors increase in frequency as the adolescent ages is concerning considering that the protective effect of cohesive family decrease as youth draw away from the family unit.

Protective factors. The two protective factors of the perceived environment are models for conventional behavior, and high control against deviant behavior (Jessor, 1998). The search criteria found no studies of models for conventional behavior. High controls against deviant behaviors were protective against marijuana and cigarette use (Graves, et al., 2005), problem drinking (Branstrom, et al., 2007), ATOD use (Cleveland, et al., 2007), and smoking (Ellickson, et al., 2008). The current literature supports high controls against deviant behaviors as protective in varied populations in relation to ATOD use and problem drinking. Studies investigating other risk behaviors related to this protective factor were not found.

\section{Personality}

The personality system contains individual level variables, rather than social factors. Behavior is based on past socialization and current social system expectations (Jessor, et al., 1968). Youth with a tolerance for deviance, who get satisfaction from an activity without suffering negative consequences, are more likely to engage in deviant behavior (Jessor, et al., 1968; Jessor \& Jessor, 1977).

Risk factors. Risk factors for this domain include low perceived life chances, low self-esteem, and risk-taking propensity (Jessor, 1998). Low perceived life chances predicted various problem behaviors (Vazsonyi, et al., 2008). Risk taking propensity was a predictor of ATOD use (Cleveland, et al., 2008) and has been associated with increased suicide ideation (Fitzpatrick, et al., 2008). Low self-esteem was predictive of both suicide ideation and attempts refine (Eskin, et al., 2007), while high self-esteem was protective against depressed mood (Costello, et al., 2008), suicide ideation (Fitzpatrick, et al., 2008; Park, et al., 2006), and suicide attempts (Fitzpatrick, et al., 2008).

Consistent with problem behavior theory, the literature supports risk factors in the personality domain as affecting behaviors, including problem behavior, depressed mood, ATOD use, suicide ideation, and suicide attempt. Individual level variables are very salient and have a constant daily presence for adolescents, who may consider themselves invincible (Elkind, 1984).

Protective factors. Protective factors in the personality domain include value on achievement, value on health, and intolerance of deviance (Jessor, 1998). Youths who reported value on health and value on achievement also reported adequate participation in physical activity and healthy eating habits (Boshoff, Dollman, \& Magarey, 2007). Value on achievement was predictive of delayed onset of smoking (Wills, et al., 2004). 
The literature has few examples specific to factors of the personality domain. It is possible that more examples of these studies exist, but the search criteria, which specified risk behaviors, did not adequately capture health-related behaviors.

\section{Behaviors}

The behavior domain has risk and protective variables, and includes both acceptable and unacceptable behaviors. Actions that meet socially acceptable norms are appropriate for adolescents. Examples include church attendance and academic achievement (Jessor \& Jessor, 1977).

Risk factors. The two risk factors in this domain include problem drinking and poor schoolwork (Jessor, 1998). No studies were found related to poor schoolwork. Support for problem drinking as an outcome, but not as a risk factor was reported. Problem drinking was predicted by various risk factors (Vazsonyi, et al., 2008) and by higher grade in school (Branstrom, et al., 2007). There is a dearth of research examining behavior domain risk factors, perhaps because problem drinking and poor schoolwork are usually outcome variables. Risk factors are often examined within larger models, thus making it difficult to identify studies specific to those variables.

Protective factors. The protective factors of the behavior system include church attendance, and involvement in school and voluntary clubs. Research in this area is limited. Religiosity has been negatively correlated with ATOD use (Feinberg, Ridenour, \& Greenberg, 2007). Adolescents who felt connected to a spiritual community reported less suicide ideation, but there was no relationship between religiosity and suicide ideation or attempt (Fitzpatrick, et al., 2008).

No literature was found regarding school and voluntary club involvement, and little evidence exists about church attendance as a protective factor. The two studies discussed were not specific to church attendance and the questions were limited in scope. Investigating both religiosity and spirituality may be a better approach, because youth may break away from traditional religion, yet remain spiritual.

\section{Current Literature Regarding Risk Behaviors}

As the theory of problem behavior evolved, risk and protective factors were separated from the risk behaviors domain (see Figure 1 ). The basic tenant that risk behavior is age dependant remains unchanged (Jessor, 1998). For example, alcohol use is unacceptable for an 18 year old, but not for a 21 year old, even though both are adolescents (Jessor \& Jessor, 1977).

\section{Problem Behavior}

The problem behavior variables include illicit drug use, delinquency, and drunken driving (Jessor, 1998). No studies reported findings on drunk driving. Risk and protective factors predict the use of illicit drugs or problems from drug use (Vazsonyi, et al., 2008), and illicit drug use has been predicted by models that include risk factors. Various factors served as protective, but the effect strength of protective factors was less than that of risk factors (Cleveland, et al., 2007). Although posited in the problem behavior theory as affected by risk and protective factors, the literature focuses on illicit drug use as a risk factor for other behaviors. Concurrent illicit drug use was strong predictor of initiation of tobacco use (Wills, et al., 2004), increased the risk of depressed mood (Costello, et al., 2008), and was associated 
with suicide ideation (Park, et al., 2006). Youth who reported marijuana use had increased rates of delinquency (Branstrom, et al., 2007). Supporting the proposition that risk and protective factors combine to produce forces that affect behavior, risk and protective factors predicted $13 \%$ of the variance in one model and $10 \%$ of the variance in another model (Vazsonyi, et al., 2008).

Illicit drug use is well represented in the literature, as a behavior and as a risk factor for the cooccurrence of other risk behaviors and risk outcomes. It is interesting that the literature search identified studies from around the world pertaining to multiple risky behaviors, yet none addressed adolescent drunk driving. Perhaps the research on drunk driving exists in the adult literature and therefore was not captured by this search.

\section{Health-Related Behavior}

Health-related behaviors include unhealthy eating, tobacco use, sedentariness, and non-use of safety belts (Jessor, 1998). The literature on unhealthy eating, sedentariness and non-use of safety belts yielded only two studies. One study addressed eating habits and physical activity related to obesity. Only $20 \%$ of the sample met the criteria for healthy eating and physical activity. The proportion of overweight children was $37.7 \%$ for males and $29.5 \%$ for females, with the expected percents of $23.3 \%$ and $19.8 \%$ respectively (Boshoff, et al., 2007). The study identified two protective factors, value on health and value on achievement, as positively related to healthy eating and adequate physical activity.

The second study examined health-related behaviors in two populations via the concept of heath-enhancing behaviors, defined as healthy eating, adequate physical activity, and the safety practices of seat belt use and bicycle helmet. More males than females were physically active, and more females than males wore helmets or seat belts. The model accounted for $45 \%$ of the variance in one sample and $41 \%$ of the variance in the other sample. A moderating effect of protective factors on risk factors was identified, suggesting that protective factors play two roles: promoting health-enhancing behaviors and buffering risk factors (Turbin, et al., 2006).

Supporting the proposition that risk and protective factors combine to create proneness towards risk behaviors, a study found that early onset smokers reported higher levels of risk factors and lower levels of protective factors than other groups. Non-smokers reported the highest levels of protective factors and the lowest levels of risk factors. Intermediate and late onset smokers reported changes in risk and protective factors, with risk factors increasing and protective factors decreasing just prior to the onset of smoking. The strongest predictors of smoking onset were concurrent use of alcohol or marijuana (Wills, et al., 2004). Tobacco use was also predicted by models including individual, peer, and family risk and protective factors. The presence of positive societal factors was protective, but the strength of the protective factors was less than that of the risk factors (Cleveland, et al., 2007).

Tobacco use literature is abundant, and although listed in the overall theory as a health-related risk behavior (Jessor, 1998), tobacco use is more often investigated as a risk factor. Smoking has been associated with school difficulty and multiple problem behaviors. Adolescents who smoked were more likely to have peers who used tobacco, had problems at school, and an important adult in their life was a smoker (Ellickson, et al., 2008).

Tobacco use can be a risk factor or a risk outcome. Tobacco use has been associated with depressed mood (Costello, et al., 2008), and suicide ideation (Park, et al., 2006). The 
connection between tobacco use and impaired mental health is evident, as demonstrated by a $69 \%$ use rate among youth requiring mental health services (Graves, et al., 2005).

Overall, the literature on health-related behaviors supports the guiding theory that risk factors are associated with participation in unhealthy activity, and that protective factors are related to a decreased frequency of such behaviors. Few studies address non-use of safety belts, and it was surprising that only one study addressed unhealthy eating or sedentariness, especially considering the trends in adolescent obesity.

\section{School Behavior}

The risky behaviors of the school behavior system include truancy, dropout, and drug use at school (Jessor, 1998). The literature does support the risk factor of problem drinking in association with truancy. Heavy drinkers of either sex were more likely to report truancy. However, the increased likelihood of truancy was limited to males when examining marijuana use (Branstrom, et al., 2007). Alternatively, early truancy predicted continued smoking (Ellickson, et al., 2008).

The literature on school behaviors reveals a general lack of current studies. It is possible that broader search criteria would identify additional studies. Most studies are school based. This raises questions about the lack respondents who have already dropped from school or were truant and who are likely to be even more adversely affected by risky behavior patterns.

\section{Current Literature Regarding Risk Outcomes}

Risk outcomes, divided into four subcategories, include a variety of health/life compromising behaviors (Jessor, 1998). The only variable in any subcategory found in the literature search was depression/suicide. The theory posits that like risk behaviors, risk outcomes result from the complex interaction of risk and protective factors.

Trajectories of depressed mood were examined using group-based modeling. Overall, participants in groups reporting any type of depressed mood were more likely to be female, report ATOD use, and/or participate in delinquent behaviors. They were less likely to report the protective factors of family cohesion, high self-esteem, and high SES (Costello, et al., 2008).

Suicide ideation was more likely to be reported by females, although suicide attempt rate did not vary by gender. The predictors of suicide ideation or attempt included the risk factors of low grade point average, and low self-esteem. The only positive protective factor was family cohesion (Eskin, et al., 2007). Two additional predictors of suicide ideation include past history of treatment for depression and previous suicide attempts (Park, et al., 2006). In an African American sample suicide ideation percent by gender was higher for females $(20.2 \%)$ than for males $(13.3 \%)$, and females were three times more likely to report suicide attempts. Adolescents reporting either suicide ideation or attempt were more likely to report risk-taking propensity and the depression (Fitzpatrick, et al., 2008).

\section{Discussion}

\section{Summary of the Literature Relating to Problem Behavior Theory}

This review of fifteen studies from nine countries demonstrated that adolescent risk behaviors and subsequent risk outcomes are worldwide issues. This supports the proposition that, although modified by developmental and cultural variables, protective and risk factors affecting youth behavior exist everywhere. Most studies support the theory by findings consistent with 
and predicted by the model. In general, risk factors are associated with risk behaviors or risk outcomes, and protective factors result in decreased participation and improved risk outcomes. Additionally, risk factors exert a greater effect than protective factors, and protective factors mediate risk factors. The exceptions to the support for risk and protective factors included no support for church attendance, and mixed or non-support for a family history of alcoholism, poverty, racial inequality, cohesive families, and models for deviant behavior.

Strength of the current literature is demonstrated by findings consistent with theory predicted outcomes. Most studies had large numbers of participants and four studies used random sample selection. Six longitudinal studies allowed findings to be compared and created trajectories. A broad spectrum of youth from differing backgrounds and a variety of tools obtained multiple variations of variables and some instruments were translated and reverse translated.

Weaknesses of the current literature include studies using cross sectional studies and nonrandom samples. This limits the ability to generalize findings and to make causal statements. Most samples included school attending adolescents, leaving out those at greater risk for deviant behaviors and risk outcomes. In studies with urban, suburban, and rural populations, no comparisons by those factors were made. The variety of tools and operational definitions makes comparisons of studies, variables, and interpretation of outcomes difficult. Additionally, large predictive models make it difficult to assess the effect of one variable.

\section{Gaps in the Current Research Base}

There are gaps in the literature, such as the lack of studies relating to interested adults, models for conventional behavior, parent-friend normative conflict, poor schoolwork, drunk driving, and involvement in schools or voluntary clubs. There are limited research findings with regard to racial inequality, church attendance, unhealthy eating, sedentariness, and non-use of seat belts. These may be true gaps or the search terms were too restrictive to capture all variables. It is interesting that the search criteria did not reveal studies related to adolescent driving behaviors and obesity.

Gaps alsoexist in sampling of populations at significantly higher risk, such as those who have dropped out of school, are incarcerated, or are homeless. Those youth have higher rates of risk behaviors and suffer more devastating effects from risk outcomes. They may also be affected differently by risk and protective factors when compared to the general population.

\section{Limitations}

This literature review has limitations including the time limit of the previous 5 years. Without the time limit additional studies would have been identified. However, the limited time period demonstrates the most current studies. Intervention models and middle school aged adolescent were not included, and may have revealed valuable information. Not all databases were searched, excluding studies from other disciplines. Additional search terms, such as unintentional injury, obesity, and physical activity might have captured non-use of seatbelts, drunk driving, unhealthy eating behaviors, and sedentariness. Key word searching does not identify all pertinent studies, depending on titles.

\section{Suggestions for Future Research}

Clearly, there are opportunities for future studies to test the problem behavior theory. To begin, studies investigating the identified gaps need to be completed. Several studies conclude, and this author agrees, that future research should carefully consider the culture and society 
the sample represents. Replication of studies from one culture to another could support the theory, or suggest potential modifications required by cultural norms. Future research should strive to develop interventions and apply findings in actual practice settings.

\section{Conclusion}

The problem behavior theory has been studied and tested for several decades. Changes and corrections to the propositions have resulted in a model that appears to be applicable worldwide. Yet more work is needed. Knowing about the effects of risk and protective factors is just touching the surface of the problem and begins to supplying the knowledge needed to develop interventions that change adolescent behaviors and ultimately their lives. Designing interventions specific to the adolescent population, which result in changes to the risk outcomes in a positive direction is the desired end result. Public health can be positively affected by intervening to decrease the risky life style choices that are built on the behavioral patterns of youth. Programs delivered during the developmental period when the establishment lifelong healthy or unhealthy patterns occur can have a powerful positive effect on individual and population health for many years to come.

\section{References}

Bartlett, R., Holditch-Davis, D., Belyea, M., Halpern, C.T., \& Beeber, L. (2006). Risk and protection in the development of problem behaviors in adolescents. Research in Nursing and Health, 29, 607-621.

Bennett, M.D. (2007). Racial socialization and ethnic identity: Do they offer protection against problem behaviors for African American youth? Journal of Human Behavior in the Social Environment, 15(2-3), 137-161.

Boshoff, K., Dollman, J., \& Magarey, A. (2007). An investigation into the protective factors for overweight among low socio-economic status children. Health Promotion Journal of Australia, $18(2), 135-142$.

Branstrom, R., Sjostrom, E., \& Andreasson, S. (2007). Individual, group and community risk and protective factors for alcohol and drug use among Swedish adolescents. European Journal of Public Health, 18(1), 12-18.

Centers for Disease Control and Prevention. (2008). 2007 National Youth Risk Behavior Survey overview. Retrieved from: http://www.cdc.gov/HealthyYouth/yrbs/pdf/yrbs07 us overview.pdf

Cleveland, M.J., Feinberg, M.E., Bontempo, D.E., \& Greenberg, M.T. (2008). The role of risk and protective factors in substance use across adolescence. Journal of Adolescent Health, 43, 157-164.

Costello, D.M., Swendsen, J., Rose, J.S., \& Dierker, L.C. (2008). Risk and protective factors associated with trajectories of depressed mood from adolescence to early adulthood. Journal of Consulting and Clinical Psychology, 76(2), 173-183.

Elkind, D. (1984). Teenage Thinking: Implications for Health Care. Pediatric Nursing, 10, 383385. 
Ellickson, P.L., Tucker, J.S., \& Klein, D.J. (2008). Reducing early smokers' risk for future smoking and other problem behaviors: Insights from a five-year longitudinal study. Journal of Adolescent Health, 43, 394-400.

Eskin, M., Ertekin, K., Dereboy, C., \& Demirkiran, F. (2007). Risk factors for and protective factors against adolescent suicidal behavior in Turkey. Crisis 2007, 28(3), 131-139.

Feinberg, M.E., Ridenour, T.A., \& Greenberg, M.T. (2007). Aggregating indices of risk and protection for adolescent behavior problems: the Communities That Care Youth Survey. Journal of Adolescent Health, 40, 506-513.

Fitzpatrick, K.M., Piko, B.F., \& Miller, E. (2008). Suicide ideation and attempts among lowincome African American adolescents. Suicide \& Life-Threatening Behavior, 38(5), 552-563.

Graves, K.N., Fernandez, M.E., Shelton, T.L., Frabutt, J.M., \& Williford, A.P. (2005). Risk and protective factors associated with alcohol, cigarette, and marijuana use during adolescence. Journal of Youth and Adolescence, 34(4), 379-387.

Jessor, R. (1998). New perspectives on adolescent risk behaviors. Cambridge, MA: Cambridge University Press.

Jessor, R., Graves, T.D., Hanson, R.C., \& Jessor, S.L. (1968). Society, personality, and deviant behavior: A study of a tri-ethnic community. New York: Holt, Rinehart and Winston, Inc.

Jessor, R., \& Jessor, S.L. (1977). Problem behavior and psychosocial development: $A$ longitudinal study of youth. New York: Academic Press.

Park, H.S., Schepp, K.G., Jang, E.H., \& Koo, H.Y. (2006). Predictors of suicidal ideation among high school students by gender in South Korea. The Journal of School Health, 76(5), 181-188.

Turbin, M.S., Jessor, R., Costa, F.M., Dong, Q., Zhang, H., \& Wang, C. (2006). Protective and risk factors in health-enhancing behavior among adolescents in China and the United States: Does social context matter? Health Psychology, 24(4), 445-454.

Vazsonyi, A.T., Chen, P., Young, M., Jenkins, D., Browder, S. Kahumosku, E., et al. (2008). A test of Jessor's problem behavior theory in a Eurasian and a Western European developmental context. Journal of Adolescent Health, 43, 555-564.

Wills, T.A., Resko, J.A., Ainette, M.G., \& Mendoza, D. (2004). Smoking onset in adolescence: A person-centered analysis with time-varying predictors. Health Psychology, 23(2), 158-167.

World Health Organization. (2008). 10 facts on adolescent health. Retrieved from http://www.who.int/features/factfiles/adolescent health/en/index.html

World Health Organization. (2009). Adolescent health. Retrieved from http://www.who.int/whr/2002/annex/en/index.html 
(C) Copyright of Journal of Youth Development $\sim$ Bridging Research and Practice. Content may not be copied or emailed to multiple sites or posted to a listserv without copyright holder's express written permission. However, users may print, download or email articles for individual use. 